\title{
Detection and identification of six Cryptospordium species in livestock in Slovakia by amplification of SSU and GP60 genes with the use of PCR analysis
}

\author{
Ol'ga Danišová', Alexandra Valenčáková', Antónia Petrincová' \\ ${ }^{1}$ Department of Biology and Genetics, University of Veterinary Medicine and Pharmacy, Košice, Slovak Republic \\ Danišová O, Valenčáková A, Petrincová A. Detection and identification of six Cryptospordium species in livestock in Slovakia by amplification \\ of SSU and GP60 genes with the use of PCR analysis. Ann Agric Environ Med. 2016; 23(2): 254-258. doi: 10.5604/12321966.1203886
}

\begin{abstract}
Introduction. In this study we examined 200 faecal samples from pigs and calves with suspected cryptosporidiosis were examined by the PCR methods: nested PCR for amplification of SSU region; nested PCR for amplification of GP60 region; and with restriction analysis of DNA (PCR-RFLP). The sequencing identified the following species: Cryptosporidium muris (2), Cryptosporidium andersoni (1), Cryptosporidium bovis (4), Cryptosporidium suis (2), Cryptosporidium scrofarum (10), mixed infection caused by C. scrofarum and C. muris (1), and Cryptosporidium parvum (10) genotype A subtype IlaA17G2R1.

Results and conclusions. The findings suggest that livestock can be an important source of zoonotic species or genotypes of Cryptosporidium, which may adversely affect the public health of human populations. This is the first time in our country that the Cryptosporidium species has been identified in livestock in Slovakia. The identification and genotyping of this pathogen in Slovakia, completes the epidemiological situation in Europe for Cryptosporidum species.
\end{abstract}

Keywords

Cryptosporidium spp., cattle, pig, zoonotic potential, gene SSU, gene GP60

\section{INTRODUCTION}

The diarrheal syndrome is a common and economically significant disease of livestock. In breeding conditions with low hygienic standards, this syndrome is known to cause high morbidity and mortality. Cryptosporidium spp. are one of several possible etiologicalagents that may be responsible for significant neonatal morbidity [1]. The main reservoir of pathogenic Cryptosporidium spp. is among livestock, especially calves, lambs, kids and weaners. Cases of Cryptosporidium infection have been reported in Slovakia only rarely. Therefore, information about the occurrence of individual Cryptosporidiumspecies and the prevalence of cryptosporidiosis is sparse.

Cryptosporidium infections in weaners and pigs are mostly asymptomatic or rarely exhibit overt clinical symptoms. Cryptosporidiosis in pigs is usually caused by three different intestinal species of Cryptosporidium: Cryptosporidium parvum, Cryptosporidium suis, and Cryptosporidium scrofarum (Cryptosporidium pig genotype II), which has been described as 'natural infections' in pigs and may be caused by Cryptosporidium specific for other hosts. The gastric Cryptosporidiummurishas been detected in pig manure collected from Irish farms [2]. In eastern China, a C. parvum mouse genotype was isolated from porcine faeces [3], whose typical natural hosts are rodents [4]. Naturally occurring Cryptosporidium infection in pigs are most commonly found in weaners more than one month old, but younger than six months of age. Infections of piglets younger than one month and in adult pigs are described less frequently.

Address for correspondence: Ol'ga Danišová, Department of Biology and Genetics, University of Veterinary Medicine and Pharmacology, Komenkého 73, 04181 Košice, Sovak Republic

E-mail: olga.danisova@uvlf.sk

Received: 15 July 2015; accepted: 23 October 2015
The course of Cryptosporidium infections in pigs is different from that in other livestock or in humans. Diarrhoea in pigs is usually a multifactorial problem and can be caused by a wide variety of pathogens (coccidia, Strongyloides sp., Salmonella spp., Clostridium perfringens, Escherichia coli, adenoviruses, rotaviruses, and circoviruses $[5,6,7])$, either separately or in combination with other opportunistic pathogens (Encephalitozoon intestinalis, Enterocytozoon bieneusi, and Cryptosporidium spp.). Experimental infections have demonstrated that pigs are susceptible to other gastric Cryptosporidium, i.e.C. meleagridis and C. hominis [8].

Unlike in pigs, the prevalence of cryptosporidiosis in calves ranges from $2.4 \%-100 \%$ worldwide [9]. Cattle are mainly infected by four Cryptosporidium species: Cryptosporidium parvum, Cryptosporidium bovis, Cryptosporidium andersoni, and Cryptosporidium deer-like genotype [10]. The zoonotic potential has been confirmed in only one species, namely, C. parvum. Other species and genotypes of Cryptosporidium reported in cattle are; Cryptosporidium ubiquitum, Cryptosporidium xiaoi and Cryptosporidium muris. The latter has a wide host range which includes mice and other rodents, some ruminants, primates, dogs, cats, rabbits and humans [11]. There has also been described a mixed infection caused by C. bovis and C. ryanae and a new genotype in the yak (Bos grunniens; 12). Studies have shown that Cryptosporidium infections in cattle are not limited by age, but by species (genotype) of Cryptosporidium, which causes these protozoan infection.

Application of the PCR method and its modifications (PCR-RFLP) with the use of appropriate primers and restriction enzymes, significantly improved diagnostics, mainly in terms of detection, identification of species and subtyping of Cryptosporidium spp. [13], because this pathogen has zoonotic potencial. Cryptosporidiosis can have an effect on the public health of humans. Identified species 
of Cryptosporidium completes the epidemiological situation in neighbouring countries and indicates the necessity for especially monitoring the zoonotic species.

\section{MATERIALS AND METHOD}

Study population - samples. Samples of faeces were collected from 100 pigs and 100 calves from two farms (Strážske, Zemplínska Teplica) in Eastern Slovakia in September 2013 and 2014, and divided into groups according to age (Tab. 1). Faecal samples were collected only from animals with clinical signs (anorexia, diarrhoea, abdominal pain, and weight loss to cachexia) indicating suspected cryptosporidiosis.

Molecular analysis - DNA isolation. Genomic DNA was extracted from the $100 \mathrm{mg}$ stool samples using the DNASorb-B Nucleic acid Extraction kit (AmpliSence), according to the manufacturer's instructions. Before extraction, the stools we homogenized to disrupt the oocysts at 6,500 rpm for 90 seconds, with the addition of $0.5-\mathrm{mm}$-glass beads, $1.0-\mathrm{mm}$ zircon beads and $300 \mu \mathrm{l}$ lysis solution in a homogenizer, Precellys 24 (Bertin Technologies, France). After purification, the DNA was stored at $20^{\circ} \mathrm{C}$ until use in the nested PCR.

Nested PCR, PCR-RFLP - Electrophoresis, Sequencing. For the nested PCR, a modified protocol $[13,14]$ was used with genus-specific primers Xiao F2/ Xiao R2 (819-825 bp) and VKSS F1/VKSS R2 (345-355 bp), and a protocol described by Leetz et al. [14] using the outer primers VKSS F1/VKSS R1 (658-662 bp) and the inner primers VKSS F2 / VKSS R2 (245-250 bp) for amplification of the SSU region of the Cryptosporidium species DNA. Secondary PCR products were analyzed by electrophoresis in 1.5\% agarose gel and visualized by UV light with a wavelength of $312 \mathrm{~nm}$ [15].

Positive samples were repeatedly analyzed by PCR-RFLP, where for restriction of the primary PCR product with the length of 819-825 bp (primers: Xiao F2/Xiao R2), two restriction enzymes were used: $S s p$ I (identification of species) and PshB I (Vsp I, identification of genotypes; Takara BIO INC., Japan) with an incubation at $37^{\circ} \mathrm{C} / 12$ hours [13].The products of restriction were separated on $2 \%$ agarose gel and visualized after staining with RedGel dye by UV light.

For confirmation of the Cryptosporidium spp. after PCRRFLP and nested PCR (VKSS primers), all positive samples were sent for sequencing. The sequences were compared with known sequences with BLAST in the NCBI database.

Samples positive for Cryptosporidium parvum were analyzed once again with nested PCR with species-specific primers gp15 F1/ gp15 R1 (980-1,000 bp) and gp15 F2/ gp15 F2/R2 (450 bp) which are used for amplification of the GP60 region and for identification of the genotype and subtype ofC. parvum. The PCR products were again sent for sequencing and the sequences genotyped.

$P C R$ reaction mix. The volumes of the PCR reaction mixtures in both cases were $50 \mu \mathrm{l}$, from which the DNA sample was $5 \mu \mathrm{l}$. In these reactions, primers with a concentration of 0.2 $\mu \mathrm{M}$ and $5 \mathrm{U}$ Taq DNA polymerases (FIREPol) were used.

The PCRs were run in a thermocycler (XP Thermal Cycler Blocks) with an initial denaturation of $95^{\circ} \mathrm{C}$ for 5 min., followed by 35 cycles of $95^{\circ} \mathrm{C}$ for $1 \mathrm{~min}$., $60 / 61 / 69^{\circ} \mathrm{C}$ for 1 min., and $72^{\circ} \mathrm{C}$ for $2 \mathrm{~min}$. A final elongation step of $72^{\circ} \mathrm{C}$ for 7 minutes was included to ensure the complete extension of the amplified products.

Annealing temperature for the used primers Xiao F2/Xiao $\mathrm{R} 2-60^{\circ} \mathrm{C}$, VKSS F1/VKSS R2 and gp15 F1/gp $15 \mathrm{R} 1-61^{\circ} \mathrm{C}$, gp15 F2/ gp $15 \mathrm{R} 2-69^{\circ} \mathrm{C}$.

PCR products were directly sequenced in both directions. Sequences were aligned and completed using ChromasPro, Bioedit and Clustal X, and compared with known sequences in the National Centre for Biotechnology Information GenBank database. The sequences generated in the presented study have been deposited in the GenBank database under accession numbers (described in the Results). The sequences

Table 1. Detected species of Cryptosporidium

\begin{tabular}{|c|c|c|c|c|c|c|c|c|c|c|}
\hline \multirow{2}{*}{ group } & & \multirow{2}{*}{$\begin{array}{l}\text { Age/ } \\
\text { category }\end{array}$} & \multirow{2}{*}{$\mathrm{n}$} & \multicolumn{4}{|c|}{ Intestinal species } & \multicolumn{2}{|c|}{ Stomach species } & \multirow{2}{*}{$\begin{array}{c}\text { Mixed } \\
\text { infection } \\
\begin{array}{c}\text { C. scrofarum } \\
\text { C. muris }\end{array}\end{array}$} \\
\hline & & & & C. parvum & C. bovis & C. suis & C. scrofarum & C. muris & C. andersoni & \\
\hline \multirow{10}{*}{ pig } & \multirow{3}{*}{ Strážske 2013} & piglets & 5 & & & & 2 & 2 & & 1 \\
\hline & & weaners & 4 & & & 2 & 2 & & & \\
\hline & & sows & 6 & & & & 1 & & 1 & \\
\hline & \multirow{2}{*}{ Zempl. Teplica 2013} & piglets & 7 & & & & & & & \\
\hline & & weaners & 27 & & & & & & & \\
\hline & \multirow{2}{*}{ Strážske 2014} & piglets & 5 & & & & & & & \\
\hline & & weaners & 12 & & & & 1 & & & \\
\hline & \multirow{2}{*}{ Zempl. Teplica 2014} & piglets & 8 & & & & & & & \\
\hline & & weaners & 26 & & & & 4 & & & \\
\hline & $\Sigma$ pigs & & 100 & & & 2 & 10 & 2 & 1 & 1 \\
\hline \multirow{6}{*}{ calf } & Strážske 2013 & $<1$ month & 5 & & 2 & & & & & \\
\hline & \multirow{2}{*}{ Zempl. Teplica 2013} & $<1$ month & 10 & 7 & & & & & & \\
\hline & & $>1$ month & 10 & 1 & 2 & & & & & \\
\hline & Strážske 2014 & $<1$ month & 9 & & & & & & & \\
\hline & Zempl. Teplica 2014 & $>1$ month & 66 & 2 & & & & & & \\
\hline & $\sum$ calves & & 100 & 10 & 4 & & & & & \\
\hline \multicolumn{2}{|c|}{$\Sigma$ animals } & & 200 & 10 & 4 & 2 & 10 & 2 & 1 & 1 \\
\hline
\end{tabular}


identified as Cryptosporidium spp are used for phylogenetic analysis and phylogenetic tree formation. The sequences were controlled by the Geneious programme and modified in the Bioedit program programme. In the phylogenetic process and evaluation of the monitored sequence, the RAxML programme was used [16]. The resulting phylogenetic tree is shown using Figtree and edited in Adobe Illustrator CC, 2014.

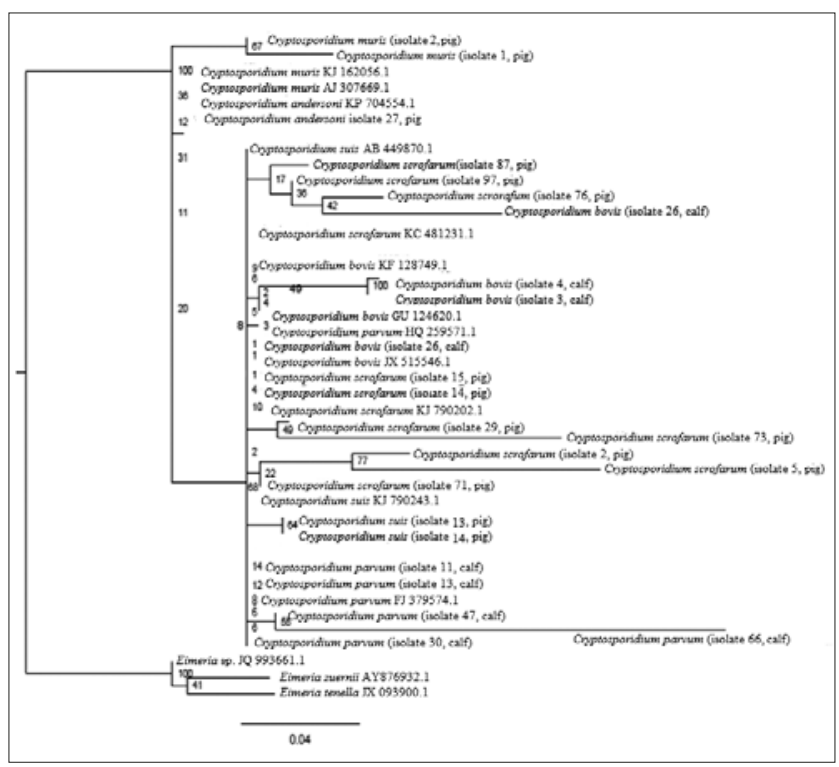

Figure 1. Evolutionary relationships among C. muris, $C$. andersoni, $C$. suis, C. scrofarum, C. parvum, C. bovis inferred from a partial fragment of the $18 \mathrm{~S}$ rRNA gene

\section{RESULTS}

In the faecal samples of animals with suspected clinical cryptosporidiosis, the presence of the following species were confirmed in pigs: C. andersoni (1; KP704554), C. suis (2; KP704556), and C. scrofarum(10; KP704557). By repeated analysis of nested PCR with primers VKSS, the species C. muris (KP704555) were also identified in two weaners, and a mixed infection with C. scrofarum and C. muris confirmed in one weaner. In calves, infections were found with the species C. bovis (4; KP704558) and C. parvum (10; KP704559) genotype A subtype IIaA17G2R1 (KP704560). Prevalence of cryptosporidiosis in calves was $15 \%$ and in pigs - $14 \%$.

The analyzed samples of the reference sequence (NCBI GenBank), and the 'outgroup' group consisted of the sequence Eimerii spp. A phylogenetic tree was constructed and the phylogenetic analysis highlighted not only the affinities and evolutionary branching between sequences of different types of Cryptosporidium spp. analysed, but also within the same species. The sequences obtained for C. parvum lie on a branch with a reference sequence of C. parvum and C. bovis analyzed sequences lie along the tree to the reference sequence of C. bovis, as well as C. suis and C. scrofarum, indicating also the close familial relationships within the intestinal species of Cryptosporidium spp. analyzed sequences. The phylogenetic tree also shows the differences in the types of gastric and intestinal species of Cryptosporidium.

\section{DISCUSSION}

By restriction analysis RFLP it is possible to diagnose and identify Cryptosporidium spp. in various hosts in a relatively short time. With RFLP analysis, 4 species of Cryptosporidium were identified, with a prevalence of $15.0 \%$ in pigs. The prevalence of Cryptosporidium infections in pigs has been reported to be $30-34 \%$, with various representations in all age categories. Cryptosporidium infections have been reported worldwide, mainly in pigs before and after weaning which were in the age category of $1.5-3$ months $[5,17]$. In older animals with a prevalence of infection of $5-12 \%$, cryptosporidiosis, it has been found to be less common in the age category of 5.5-6 months [18]. The presence of Cryptosporidium in older pigs varies. Xiao et al. [19], Atwill et al. [20] amnd Maddox-Hyttel et al. [17] reported the total absence of disease in this age category. On the contrary, in 2007-2008, Kváč et al. (unpublished results) detected in the Czech Republic a prevalence higher than 21\%, and Quilez et al. [21] reported prevalences of $30-34 \%$ in $2-6$ months old pigs.

The infection in pigs is primarily localized in the small and large intestines. Vítovec et al. [22] identified in their study a similarity of gastric Cryptosporidium: C. muris and C. andersoni, withC. suis, oocysts, which were localized in the glands of the lymphogranular complex in the submucosa of the colon and the rectum. C. suis frequently becomes disseminated to other parts of the gastrointestinal tract. In addition to the gastrointestinal tract, Cryptosporidium of pigs can infect surrounding organs. C. muris has a wide host range that includes mainly mice and other rodents that are possible reservoir of Cryptosporidium infections and have zoonotic potential. C. muris has been identified in pig faeces in the Czech Republic [23], in China [3], in pig manure (USA; 2) and in swine waste lagoons and sprayed fields (USA; 24). In their study, Kváč et al. [25] indicated that infections caused by $C$. muris in pigs after weaning, is not active, and therefore this group is not susceptible to infection by this species, but $C$. suis and C. scrofarum are highly pathogenic for pigs and the presence of these species in pigs after weaning was also found in the presented study.The infection of piglets by $C$. muris and mixed infection with C. muris and C. scrofarum, may indicate an active cryptosporidiosis in this age group due to the lack of passive immunity which may cause a high susceptibility to the pathogens, including parasitic infections.

The important aspect of the current work is the detection ofC. muris, confirmed only with the pair of primers VKSS that detects C. muris and alsoC. parvum, C. hominis, C. andersoni, C. meleagridis, C. baileyi, C. serpentis and C. wrairi $[14,26]$. Based on these results, it is suspected that the primer VKSS is probably more sensitive for small fragments of DNA and specific for C. muris in the PCR analysis.

The fact that C. scrofarum was identified not only in weaners, but also in one sow, correlates with the results of studies by Kváč et al. [27] and Quilez et al. [21]. It is also important to pay attention to the fact that this specie was diagnosed in an immunocompromised human [28], which confirms the zoonotic potential of C. scrofarum. From an epidemiological point of view, it would therefore be desirable to monitor the occurrence of this species in the human population.

Other Cryptosporidium species with zoonotic potential in the presented study group of animals were identified 
in calves. The prevalence of Cryptosporidium infections in calves on the farms in this study was $14 \%$. However, Santín et al. [29], Rieux et al. [30] detected $92-100 \%$ prevalence of Cryptosporidium infections in calves. The difference in the prevalence of individual Cryptosporidium species is closely linked not only to the geographic locality and the climatic conditions, but also with selection of the study group, the type of breeding and the diagnostic methods used. Numerous studies have reported infections caused by C. bovis (43.08\%), C. parvum (36.92\%), C. ryanae (7.69\%) as the most common in calves younger than one month of age $[30,31,32,33]$, which was also shown by the presented study with a prevalence of infection by C. parvum of 35\%. Kváč et al. [34], Fayer et al. [34], and Santín et al. [32] described in their studies that $80-90 \%$ of the calves under one month of age with clinical cryptosporidiosis were infected by C. parvum. In the current study, not only $C$. parvum were identified we identified, but also infections caused by $C$. bovis in both groups of calves.

The most widespread subtypes of Cryptosporidium parvum in Europe are IIaA18G2R1, which is common in calves in the surrounding countries of Hungary [36], Sweden [37] and France [30], or the subtype IIaA15G2R1 reported not only in the cattle, but also in humans in Portugal [38], Slovenia [39], Netherlands [40] and France [41, 42] which indicates a possible zoonotic potential.

Genotyping allowed identification of subtype IIaA17G2R1, detected only in calves in Europe, in Northern Ireland [43], Germany [44], Italy [45] and Spain [46], as well as in Canada [47] and the USA [48]. The infection caused by this subtype was confirmed in goats in China [49], in 22 calves, 2 pigs and 47 humans in North Carolina, USA [50], and in humans in Australia with a prevalence as high as $47.6 \%$ [51].

The detection and identification of subtype C. parvum IIaA17G2R1 indicates another possible zoonotic potential, and draws attention to calves that can be an important source of infection causing cryptosporidiosis which, in turn, can affect the public health of humans. The repeated detection the C. scrofarum species in pigs in Strážske and C. parvum species in calves in Zemplínska Teplica points to persistent infection on the arms in Slovakia.

This is the first time that the Cryptosporidiumin species has been identified in livestock in Slovakia, and the identification and genotyping of this pathogen in that country completes the epidemiological situation in Europe.

\section{Acknowledgments}

The study was supported by Grant No. 1/0063/13, from VEGA, the Scientific Grant Agency of the Slovakian Ministry of Education in Bratislava.

\section{Ethical clearance}

The study was approved by the Ethics Committee of University of Veterinary Medicine and Pharmacy, Kosice, Slovak Republic. All research met ethical and regulatory guidelines, including adherence to the legal requirements of the study country. All proposed methods for the handling and treatment of animals were in accordance with the Public Notice of the Slovak Republic (No. 23/2009 of 14 January 2009), concerning the requirements for the protection of animals used for experimental or other scientific purposes.

\section{REFERENCES}

1. Mcanulty JM, Fleming DW, Gonzales AM. A community-wide outbreak of cryptosporidiosis associated with swimming at a wave pool. J Am Med Associat. 1994; 272: 1597-1600.

2. Xiao L, Moore JE, Ukoh U, Gatei W, Lowery CJ, Murphy TM, Dooley JS, Millar BC, Rooney PJ, Rao JR. Prevalence and identity of Cryptosporidium spp. in pig slurry. Appl Environ Microbiol. 2006; 72: 4461-4463.

3. Chen F, Huang K.Prevalence and phylogenetic analysis of Cryptosporidium in pigs in eastern China. Zoonoses Public Health. 2007; 54: 393-400.

4. Hůrková LA, Modrý D.Cryptosporidium muris - původce žaludeční kryptosporidiózy hlodavců. Veterinářství. 2003; 53: 230-232.

5. Sanford SE. Enteric cryptosporidial infection in pigs: 184 cases (19811985). J Am Vet Med Assoc. 1987; 190: 695-698.

6. Enemark HL, Ahrens P, Bille-Hansen V, Heegaard PMH, Vigre H, Thamsborg SM, Lind P.Cryptosporidium parvum infectivity and pathogenicity of the 'porcine' genotype. Parasitol. 2003; 126: 407-416.

7. Núñez A, Mcneilly F, Perea A, Sánchez-Cordón PJ, Huerta B, Allan G, Carrasco L. Coinfection by Cryptosporidium parvum and porcine circovirus type 2 in weaned pigs. J Vet Med B Infect Dis Vet Public Health. 2003; 50: 255-258.

8. RommelM, EckertJ, KutzerE, Boch J, Supperer R. Veterinärmedizinische. Parasitologie Parey, 2000; 431-436.

9. Castro-Hermida JA, Almeida A, Gonzales-Warleta M, Corrlia De Costa JM, Rumbo-Lorenzo C, Mezo M. Occurrence of Cryptosporidium parvum and Giardia duodenalis in healthy adult domestic ruminants. Parasitol Res. 2007; 101(5): 1443-1448.

10. Feng Y, Ortega Y, He G, Das P, Xu M, Zhang X, Fayer R, Gatei W, Cama $\mathrm{V}$, Xiao L. Wide geographic distribution of Cryptosporidium parvum and deer like genotype in bovines. Vet Parasitol. 2007; 144: 1-9.

11. Xiao L, Ryan UM.Cryptosporidiosis: an update in molecular epidemiology. Curr Opin Infect Dis. 2004b; 17: 483-90.

12. Ma J, Cai J, Ma J, Feng Y, Xiao L. Occurrence and molecular characterization of Cryptosporidium spp. in yaks (Bos grunniens) in China. Vet Parasitol. 2014; 202(3-4): 113-118.

13. Xiao L, Morgan UM, Limor J, Escalante A, Arrowood M, Shulaw W, Thompson RC, Fayer R, LalAA. Genetic diversity withinCryptosporidium parvum andrelated Cryptosporidium species. Appl Environ Microbiol. 1999; 65: 3386-3391.

14. Leetz AS, Sotiriadou I, Ongerth J, Karanis P. An evaluation of primers amplifying DNA targets for the detection of Cryptosporidium spp. using C. parvum HNJ-1 Japanese isolate in water samples. Parasitol Res. 2007; Sep;101(4): 951-962.

15. Xiao L, Bern C, Limor J, Sulaiman I, Roberts J, Checkley W, Cabrera L, Gilman RH, Lal AA. Identification of 5 types of Cryptosporidium parasites in children in Lima, Peru. J Infect Dis. 2001; 183: 492- 97.

16. Stamatakis A, Hoover P, Rougemont J. Systematic Biology. 2008; 75(5): $758-771$.

17. Maddox-HyttelC, Langkjaer RB, EnemarkHL, Vigre H.Cryptosporidium and Giardia in different age groups of Danish cattle and pigs occurrence and management associated risk factors. Vet Parasitol. 2006; 141: 48-59.

18. Suárez-Luengas L, Clavel A, Quílez J, Goñi-Cepero MP, Torres E, Sánchez-Acedo C, Del Cacho E.Molecular characterization of Cryptosporidium isolates from pigs in Zaragoza (northeastern Spain). Vet Parasitol. 2007; 148: 231-235.

19. Xiao L, Herd RP, McClure KE. Periparturient rise in the excretion of Giardia cysts and Cryptosporidium parvum oocysts as a source of infection for lambs. J Parasitol. 1994; 80: 55-59.

20. Atwill ER, Sweitzer RA, Pereira MG, Gardner IA, Van Vuren D, Boyce WM. Prevalence of and associated risk factors for shedding Cryptosporidium parvum oocysts and Giardia cysts within feral pig populations in California. Appl Environ Microbiol. 1997; 63: 3946-3949.

21. Quílez J, Sánchez-Acedo C, Clavel A, Del Cacho E, López-Bernad F. Prevalence of Cryptosporidium infections in pigs in Aragón (northeastern Spain). Vet Parasitol.1996; 67: 83-88.

22. Vítovec J, Hamadejová K, Landová L, Kváč M, Květoňová D, Sak B. Prevalence and pathogenicity of Cryptosporidium suis in pre- and post-weaned pigs. J Vet Med B. 2006; 53: 239-243.

23. Kváč M, Sak B, Hanzlíková D, Kotilová J, Kvetonová D. Molecular characterization of Cryptosporidium isolates from pigs at slaughterhouses in South Bohemia, Czech Republic. Parasitol Res. 2009a; 104(2): 425-428.

24. Jenkins MB, Liotta JL, Lucio-Forster A, Bowman DD. Concentrations, viability, and distrribution of Cryptosporidium genotypes in lagoons of 
swine facilities in the Southern Piedmont and in coastal pain watersheds of Georgia. Appl Enviroment Microbiol. 2010 Sep;76(17): 5757-63

25. Kváč M, Kestř́ánová M, Květoňová D, Kotková M, Ortega Y, McEvoy J, Sak B. Cryptosporidium tyzzeri and Cryptosporidium muris originated from wild West-European house mice (Mus musculus domesticus) and East-European house mice (Mus musculus musculus) are non-infectious for pigs. Exp Parasitol. 2012; May; 131(1): 107-10.

26. Hasajová A, Valenčáková $A$, Malčeková $B$, Danišová $O$, Halán $M$, Goldová M, Sak B, Květoňová D, Kváč M, Halánová M. Significantly highter occurrence of Cryptosporidium infection in Roma children compared with non. Roma children in Slovakia. Eur J Clin Microbiol Infect Dis. 2014 Aug; 33(8): 1401-1406.

27. Kváč M, Hanzlíková D, Sak B, Kvetonová D. Prevalence and age-related infection of Cryptosporidium suis, C. muris and Cryptosporidium pig genotype II in pigs on a farm complex in the Czech Republic. Vet Parasitol. 2009; Mar 23; 160(3-4): 319-322.

28. Kváč M, Kvetonová D, Sak B, Ditrich O. Cryptosporidium pig genotype II in immunocompetent man. Emerg Infect Dis. 2009b Jun; 15(6): 982-983.

29. Santín M, Trout J, Xiao L, Zhou L, Greiner E, Fayer R. Prevalenceand age related variation of Cryptosporidium species and genotypes indairy calves. Vet Parasitol. 2004; 122: 103-117.

30. Rieux A, Paraud C, Pors I, Chartier C. Molecular characterization of Cryptosporidium isolates from beef calves under one month of age over three successive years in one herd in western France.Vet Parasitol. 2014May; 28; 202(3-4): 171-179.

31. Bednarska M, Bajer A, Siński E. Calves as a potential reservoir of Cryptosporidium parvum and Giardia sp. Ann Agric Environ Med. 1998; 5(2): 135-8.

32. Santín M, Trout JM, Fayer R. A longitudinal study of cryptospo-ridiosis in dairy cattle from birth to 2 years of age. Vet Parasitol. 2008; 155: $15-23$.

33. Coklin T, Uehlinger FD, Farber JM, Barkema HW, O'Handley RM, Dixon BR. Prevalence and molecular characterization of Cryptosporidium spp. in dairy calves from 11 farms in Prince Edward Island, Canada. Vet Parasitol. 2009; 160: 323-326.

34. Kváč M, Kouba M, Vítovec J. Age-related and housing-dependence of Cryptosporidium infection of calves from dairy and beefherds in South Bohemia, Czech Republic. Vet Parasitol. 2006; 137: 202-209.

35. Fayer R, Santín M, Trout JM. Cryptosporidium ryanae n. sp. (Apicomplexa: Cryptosporidiidae) in cattle (Bos taurus). Vet Parasitol. 2008; 156: 191-198.

36. Plutzer J, Karanis P. Genotype and subtype analyses of Cryptosporidium isolates from cattle in Hungary. Vet Parasitol. 2007; 146: 357-362.

37. Silverlås $\mathrm{C}$, Bosaeus-Reineck $\mathrm{H}$, Näslund $\mathrm{K}$, Björkman C. Is therea need for improved Cryptosporidium diagnostics in Swedish calves? Int J Parasitol. 2013; 43: 155-161.
38. Alves M, Xiao L, Antunes F, Matos O. Distribution of Cryptosporidium subtypes in humans and domestic and wild ruminants in Portugal. Parasitol Res. 2006; 99: 287-292.

39. Soba B, Logar J. Genetic classification of Cryptosporidium isolatesfrom humans and calves in Slovenia. Parasitol. 2008; 135: 1236-1270.

40. Wielinga PR, de Vries A, Van der Goot TH, Mank T, Mars MH, Kort-beek LM, van der Giessen JW. Molecular epidemiology ofCryptosporidium in human and cattle in the Netherlands. Int J Parasitol. 2008; 38: 809-817.

41. Follet J, Guyot K, Leruste H, Follet-Dumoulin A, HammoumaGhelboun O, Certad G, Dei-Cas E, Halama P.Cryptosporidium infection in a veal calf cohort in France: molecular characterization of species in a longitudinal study. Vet Res Dec. 2011; 2; 42:116.

42. Rieux A, Paraud C, Pors I, Chartier C. Molecular characterizationof Cryptosporidium isolates from pre-weaned calves in western Francein relation to age. Vet Parasitol. 2013b; 197: 7-12.

43. Thompson HP, Dooley JS, Kenney J, Mccoy M, Lowery JE, Moore JE, Xiao L. Genotypes and subtypes of Cryptosporidium spp. in neonatal calves in Northern Ireland. Parasitol Res. 2007; 100: 619-624.

44. Broglia A, Reckinger S, Cacció SM, Nöckler K. Distribution of Cryptosporidium parvum subtype in calves in Germany. Vet Parasitol. 2008; 14; 154(1-2): 8-13.

45. Duranti A, Cocció SM, Pozio E, Di Egidio A, De Curtis M, Battisti A, Scaramozzino P. Risk factors associated with Cryptosporidium parvum infection in cattle. Zoonoses Public Health. 2009; 56(4): 176-182.

46. Quílez J, Sánchez-Acedo C, Clavel A, Del Cacho E, López-Bernad F. Prevalence of Cryptosporidium infections in pigs in Aragón (northeastern Spain). Vet Parasitol. 1999; 67:83-88.

47. Trotz-Williams LA, Martin DS, Gatei W, Cama V, Peregrine AS, Martin SW, Nydam DV, Jamieson F, Xiao L. Genotype and subtype analyses of isolates from dairy calves and humans in Ontario. Parasitol Res. 2006; 99: 346-352.

48. Xiao L, Zhou L, Santin M, Yang W, Fayer R. Distribution of Cryptosporidium parvum subtypes in calves in eastern United States. Parasitol Res. 2007; 100: 701-706.

49. Mi R, Wang X, Huang Y, Zhou P, Liu Y, Chen Y, Chen J, Zhu W, Chen Z. Prevalence and molecular characterization of Cryptosporidium in Goats across four provincial level area in China. PLOS One. 2014; 24; 9(10): e111164.

50. Center for Disease Control and Prevention (CDC).Cryptosporidium Outbreak at summer camp - North Carolina. MMWR Mord Mortal Wkly Rep. 2011; 60(27): 918-922.

51. Koehler AV, Brandbury RS, Stevens MA, Haydon SR, Jex AR, Gasser RB. Genetic characterization of selected parasites from people with histories of gastrointestinal disorders using a mutation scanningcoupled approach. Electrophoresis. 2011; 34(112): 1720-1728. 